\title{
The protective functions of progesterone system of hormonal regulation in higher plants
}

\author{
Shpakovski G.V. ${ }^{1 *}$, Babak O.G. ${ }^{2}$, Spivak S.G. ${ }^{2}$, Baranova E.N. ${ }^{3}$, Kubrak S.V. ${ }^{2}$, \\ Shpakovski D.G. ${ }^{1}$, Klykov V.N. ${ }^{1}$, Slovokhotov I.Yu. ${ }^{1}$, Khaliluev M.R. ${ }^{3}$, \\ Tereshonkova T.A. ${ }^{4}$, Kilchevsky A.V. ${ }^{2}$, Shematorova E.K. ${ }^{1}$ \\ ${ }^{1}$ Shemyakin-Ovchinnikov Institute of Bioorganic Chemistry, RAS, Moscow, Russia \\ ${ }^{2}$ Institute of Genetics and Cytology, NASB, Minsk, Belarus \\ ${ }^{3}$ All-Russia Research Institute of Agricultural Biotechnology, Moscow, Russia \\ ${ }^{4}$ Federal Research Vegetable Center, VNIISSOK, Odintsovo region, Moscow district, Russia \\ *e-mail:gvs@ibch.ru
}

We have established that one of the most important functions of the ancient progesterone system of steroid hormonal regulation preserved in plants along with the brassinosteroids is protection from biotic and abiotic stresses. It is shown that the expression of the mammalian CYP11A1 cDNA of cytochrome $\mathrm{P}^{4} 50_{\text {scc }}$ in transgenic tomato plants increases their resistance to a wide range of biotic stress factors: phytopathogens Botrytis cinerea, Alternaria spp., Oidium neolycopersici and Cladosporium fulvum. Plants of line No. 7 in the generations T1 to T3 showed almost no signs of infections by all the above mentioned pathogens: vegetative organs of plants remained intensely green before the end of the vegetation period, which ceased only with the onset of frost. Elevated synthesis of endogenous progesterone increases resistance of Solanaceae plants (tomato, tobacco) also to abiotic stresses (drought, salinization). We even have observed the phenomenon of targeted protection of mitochondria of mesophyll cells in CYP11A1 transgenic tobacco plant leaves after NaCl-induced stress damage (Proc. Latv. Acad. Sci. Section B., 2018;72(6):334-340). Taken together, our data indicate that progesterone system of hormonal regulation in higher plants (BMC Plant Biol., 2017;17(Suppl 1):189) is important for nonspecific, general protection against biotic and abiotic stresses. Mitochondrial cytochrome CYP11A1 is able to provide direct protection of these cell organelles in the leaves of plants under salinity treatment.

Acknowledgements: The work was supported by grants from the Russian Foundation for Basic Research (projects No. 18-04-01262 and No. 18-54-00038) and BRFBR (project No. B18R-135). 